\title{
Pantothenol and the burning feet syndrome
}

\author{
By S. W. BIBILE, N. D. W. LIONEL, ROHINI DUNUWILLE \\ AND GNANA PERERA \\ Department of Physiology and Pharmacology, University of Ceylon, Colombo
}

(Received 21 May 1957)

Burning and aching of the extremities are often found in certain nutritional disorders of the nervous system and in diabetic neuropathy; these symptoms always dominate the clinical picture of a peripheral neuropathy known as the burning feet syndrome. An excellent description of this syndrome was given by Smith \& Woodruff (I95 I) who observed several cases in malnourished persons in Japanese prison camps during the Second World War. Gopalan (1946) reported its occurrence in India and claimed successful treatment with calcium pantothenate. According to Smith \& Woodruff the syndrome was characterized by burning and aching of the feet, mild at first but soon becoming severe and spreading up the legs to include the knee joints and often involving the hands. There were few objective neurological signs. Gopalan described cases with very similar sensory manifestations but there was no muscular weakness or anaesthesia and the tendon reflexes were normal.

Smith \& Woodruff obtained improvement but not complete cure by adding rice polishings and yeast to the diet, which suggested that a deficiency of some vitamin Bcomplex factor was responsible for the disease. There was also some improvement when thiamine or nicotinamide was administered. But their results were inconclusive and they were unable to elucidate the aetiological factor because other preparations of the B-vitamins were almost unobtainable in their prison camps. They state that their failure was not surprising because some years later the work of Gopalan appeared 'to have determined the identity of this factor, for, failing with vitamin $B_{1}$, nicotinic acid and riboflavin, he cured 53 cases with amazing rapidity by the daily injection of $40 \mathrm{mg}$. of calcium pantothenate'. Since then pantothenic acid has invariably been used to treat patients with the burning feet syndrome, even though there is still a considerable difference of opinion regarding its efficacy.

Cases of the burning feet syndrome are commonly found in Ceylon among the rural population whose economic level is low and whose diets are inadequate in several respects (Nichols \& Nimalasuriya, I94I; Bibile, Cullumbine, Watson \& Wickremanayake, I949). In the nutrition surveys made by these investigators the pantothenic-acid content of the diets was not determined, and, in order to find out whether a deficiency of this vitamin is an aetiological factor in the syndrome, we carried out a controlled therapeutic trial. Although Gopalan adopted a similar approach to this problem his investigation suffered from the absence of controls. 


\section{EXPERIMENTAL}

The trial was conducted at a government rural hospital. The quantity of drugs made available to us was sufficient for a trial on sixty patients, who were divided into three groups. Twenty of them received the drug by injection, twenty by oral administration and twenty served as controls.

Selection of patients. One of us (N.D.W.L.) was responsible throughout for the selection of patients in order to ensure uniformity of clinical material. Patients were selected from amongst those who attended the regular outpatients' clinic at the rural hospital. Those who complained chiefly of burning and aching of the extremities without being asked leading questions were examined in detail by N.D.W.L.

The criteria on which patients were selected for inclusion in the trial were as follows:

(I) The principal complaint was burning and aching of the extremities.

(2) There were no objective neurological signs other than alteration of tendon reflexes or absent plantar reflexes. Patients with muscular wasting, objective sensory disturbances or abnormalities of posture and gait were excluded from the trial.

(3) Those found to be suffering from circulatory disturbances or orthopaedic abnormalities of the extremities, from glycosuria or from marked anaemia ( $\mathrm{Hb}$ under $50 \%$ ) were excluded from the trial.

In order to select the sixty patients required for the trial, I 50 patients were examined.

Treatment. The preparation used was pantothenol, the alcohol corresponding to pantothenic acid. It was supplied in ampoules for injection and as lozenges for oral administration. Each ampoule contained $500 \mathrm{mg}$ pantothenol in $2 \mathrm{ml}$. solution and each lozenge contained $100 \mathrm{mg}$. The control injections were supplied in similar ampoules containing $2 \mathrm{ml} .25 \%$ propylene glycol which was chosen because in viscosity and appearance it was indistinguishable from pantothenol. The control lozenges contained $100 \mathrm{mg}$ propylene glycol, and they were indistinguishable from the pantothenol lozenges both in appearance and taste. These precautions were taken to prevent the patient as well as the person administering the drug from identifying the control substances from the preparations of pantothenol.

In order to prevent a recognition of treatment groups, every patient received injections as well as lozenges in the following manner: group 1 , pantothenol injections and control lozenges; group 2, control injections and pantothenol lozenges; group 3 , control injections and control lozenges.

The three treatment groups were listed in random order by the use of random sampling numbers, keeping twenty patients to each treatment group. By means of this list the combination of ampoules and lozenges corresponding to each treatment group was introduced into boxes numbered $\mathrm{I}-60$. The boxes were assigned to patients in the order in which they were accepted for trial. These measures ensured a random allocation of patients into treatment groups.

When a patient was accepted for trial, he was informed that treatment would have to be taken twice a week without interruption for 4 weeks. On the day of acceptance for trial and on each subsequent visit he received the contents of an ampoule 
intramuscularly and chewed five lozenges in our presence. Therefore, patients in group I received eight injections of pantothenol in doses of $500 \mathrm{mg}$ each, patients in group 2 received eight $500 \mathrm{mg}$ doses of pantothenol orally and those in group 3 received control substances on each of their eight visits. At each visit the patient was questioned about his symptoms in order to assess the effect of treatment. Four patients who failed to complete the course of treatment were excluded from the analysis of results.

\section{RESULTS}

Clinical manifestations. Table I summarizes the incidence of various manifestations and also shows the comparability of treatment groups before the beginning of therapy.

Table I. Comparison of the three treatment groups at the beginning of the trial

\begin{tabular}{|c|c|c|c|c|}
\hline \multirow[b]{2}{*}{ Symptom } & \multicolumn{4}{|c|}{ No. of patients showing symptom } \\
\hline & $\begin{array}{c}\text { Group I } \\
\text { (pantothenol } \\
\text { by injection) }\end{array}$ & $\begin{array}{c}\text { Group } 2 \\
\text { (pantothenol } \\
\text { by mouth) }\end{array}$ & $\begin{array}{l}\text { Group } 3 \\
\text { (placebo) }\end{array}$ & $\begin{array}{c}\text { All } \\
\text { groups }\end{array}$ \\
\hline Burning: feet & 19 & 19 & I 8 & 56 \\
\hline hands & 5 & 8 & 6 & I9 \\
\hline eyes & 9 & 9 & 8 & 26 \\
\hline trunk & 4 & 4 & 4 & 12 \\
\hline epigastrium & 3 & 2 & 3 & 8 \\
\hline Aching: legs & 14 & I4 & 10 & $3^{8}$ \\
\hline arms & 8 & Io & IO & 28 \\
\hline joints & 5 & 4 & 7 & I6 \\
\hline Giddiness & 8 & 8 & 7 & 23 \\
\hline Fatigue & 3 & 3 & 5 & I I \\
\hline Excessive sweating & 5 & 3 & 3 & I I \\
\hline Previous remissions & 5 & 3 & 7 & I 5 \\
\hline Absent knee jerk or ankle jerk & 3 & 6 & 3 & 12 \\
\hline Absent plantar reflex & 8 & 8 & 8 & 24 \\
\hline \multicolumn{5}{|l|}{ Sex distribution: } \\
\hline Male & 7 & 6 & 7 & 20 \\
\hline Female & 12 & 13 & I I & 36 \\
\hline Mean duration of disease (months) & I8 & 30 & 44 & - \\
\hline Mean age (years) & 42 & 38 & 44 & 一 \\
\hline
\end{tabular}

Burning and aching were found to occur more commonly in the lower than in the upper limbs. The patients were not able to define the area of burning and aching precisely, but indicated the affected areas vaguely by running their palms over them. The discomfort varied in intensity throughout the day. In most patients it became worse at night and interfered with sleep and in a few it was worst at midday. In an attempt to obtain relief the patients often used such measures as fanning the feet or wrapping them in wet towels or bathing in cold water, usually without much effect. About half the patients complained of a diffuse burning sensation in the eyes. A few complained of a diffuse epigastric burning which was unrelated to meals. One-third of the patients said that they had experienced remissions spontaneously or after taking outpatient treatment, which had consisted of administering a 'tonic' mixture containing ferric ammonium citrate and liquor arsenicalis. 
Nearly half the patients suffered from giddiness and a fifth of them complained of fatigue which made work difficult.

None had exaggerated tendon reflexes. The knee jerk and ankle jerk were absent in $21 \%$ of cases. The plantar reflex could not be elicited in nearly half the patients and was elicited with difficulty in the remainder. This was probably due to the thick and roughened skin over the soles of feet of people accustomed to walking barefoot for several miles every day.

Although the patients were allocated at random into treatment groups, the distribution of various clinical manifestations between the groups turned out to be satisfyingly even, which was also true for age and sex distribution. But the mean duration of the disease turned out to be longest in the control group and shortest in the injected group.

Effects of treatment. The effects of treatment were analysed at the conclusion of the trial. The list which was initially used to allocate patients to treatment groups and which had been kept confidential during the trial was then consulted to ascertain the treatment given to each patient.

On the basis of their response to treatment, patients were divided into three categories: (I) cured, when burning and aching disappeared completely within the 4 weeks of treatment; (2) improved, when burning and aching definitely diminished, or when one disappeared but not the other; (3) no change, when burning and aching remained unchanged after 4 weeks of treatment.

\section{Table 2. Results of treatment}

\begin{tabular}{|c|c|c|c|c|}
\hline \multirow[b]{2}{*}{ Group . } & \multirow{2}{*}{$\begin{array}{l}\text { No. } \\
\text { remaining } \\
\text { in group* }\end{array}$} & \multicolumn{3}{|c|}{ No. of patients } \\
\hline & & Cured & Improved & Unchanged \\
\hline I (pantothenol by injection) & 19 & 5 & 8 & 6 \\
\hline 2 (pantothenol by mouth) & 19 & 4 & 5 & Io \\
\hline 3 (placebo) & 18 & 8 & 3 & 7 \\
\hline
\end{tabular}

Table 2 summarizes the results of treatment. The table shows that among patients who were cured there were more controls than those treated with injections or lozenges. The reverse was true with patients who were improved. But these differences are small and statistical calculation $\left(\chi^{2}=5.01\right.$ for 4 D.F.; $\left.P, 0.3^{-0.2}\right)$ indicates that they were most probably due to chance variations.

If patients who were cured and improved are considered together as against those who showed no change, the differences between the treatment groups become smaller still and statistical calculation $\left(\chi^{2}=1 \cdot 73\right)$ indicates an even greater likelihood that they have arisen by chance.

None of the patients experienced a worsening of their symptoms during treatment.

Table 3 was constructed in order to find out whether patients showing any particular clinical features before treatment tended selectively to report cure, improvement or absence of change.

The figures in this table are not suggestive of any such association, except that the average duration of the disease was less in patients who were cured than in patients who 
were partially cured or not cured. But this difference is not statistically significant on account of the wide variability in the duration of the disease.

At the conclusion of the trial some of the remaining ampoules and lozenges were dispatched to the manufacturer who reported that the preparations had retained their full potency.

Table 3. Comparison of initial symptomatology in patients reporting cure, improvement and absence of change

\begin{tabular}{|c|c|c|c|}
\hline \multirow[b]{2}{*}{ Symptom } & \multicolumn{3}{|c|}{ No. of patients } \\
\hline & Cured & Improved & Unchanged \\
\hline Burning: feet & 17 & 16 & 23 \\
\hline hands & 4 & 8 & 7 \\
\hline eyes & 7 & 8 & II \\
\hline trunk & 3 & 4 & 5 \\
\hline epigastrium & 0 & 2 & 6 \\
\hline Aching: legs & 13 & 9 & 16 \\
\hline arms & 9 & 8 & II \\
\hline joints & 2 & 4 & Io \\
\hline Giddiness & 9 & 5 & 9 \\
\hline Fatigue & 3 & 5 & 3 \\
\hline Excessive sweating & 3 & 5 & 3 \\
\hline Previous remissions & 4 & 4 & 7 \\
\hline Absent knee jerk or ankle jerk & 2 & 4 & 6 \\
\hline Absent plantar reflex & 7 & 6 & Io \\
\hline Sex distribution: & & & \\
\hline Male & 6 & 6 & 8 \\
\hline Female & II & 10 & I5 \\
\hline Mean duration of disease (months) & 19 & 35 & 36 \\
\hline Mean age (years) & 44 & 41 & 41 \\
\hline
\end{tabular}

DISCUSSION

This investigation was carried out during a 2-month university vacation. We had expected that pantothenol would cure the burning feet syndrome with the same effectiveness that Gopalan claimed for calcium pantothenate. A group treated by oral administration was introduced to find out whether in comparison with the injected groups the results would indicate an interference with intestinal absorption of pantothenic acid, as has been reported for nicotinic acid in maize-eating people.

The results, however, did not show a significant difference in the cures obtained between control and treated groups of patients, which contradicts Gopalan's findings. He obtained complete cure within 2 weeks of beginning treatment. To be on the safe side, we extended the period of treatment to 4 weeks.

Gopalan cured his patients by the administration of calcium pantothenate, whereas pantothenol was the substance administered in our trial. Could this difference have accounted for the contradictory results? It is unlikely because both substances are converted into pantothenic acid in the body, and, from the point of view of stability and physiological availability, pantothenol is slightly superior to calcium pantothenate (Burlet, 1944; Rubin, 1948; Rubin, Cooperman, Moore \& Scheiner, 1948). The dose of pantothenol administered was large in comparison to the estimated daily require- 
ment of pantothenic acid, which is around $5 \mathrm{mg}$. Smaller doses administered every day would have been a better procedure, but patients were unable to come so frequently for treatment. Therefore $500 \mathrm{mg}$ were given twice weekly.

Although there seems to have been no difference in the syndrome treated by Gopalan and by us, it is possible that these symptoms have different aetiologies.

Table 3 shows that patients who were cured had a shorter duration of symptoms than those who showed no change. Smith \& Woodruff (I95I) reported a similar observation in patients who were treated by them at Selarang. It is possible that a short duration of the disease is associated with rapid cure, but we do not wish to emphasize this point, because these patients have a poor memory when it comes to remembering dates. For instance, it would be exceptional for a patient to remember his year of birth, so that statements regarding age or duration of symptoms are usually unreliable.

We conclude, therefore, that pantothenic-acid deficiency was not the cause of the burning feet syndrome in the patients investigated. At the next opportunity we propose using the whole vitamin $B$ complex to repeat a therapeutic trial on similar lines.

\section{SUMMARY}

I. A controlled clinical trial to test the efficacy of pantothenol in the burning feet syndrome was carried out in a rural area in Ceylon.

2. Sixty patients, selected for trial on the basis of predetermined clinical criteria, were allocated at random into three treatment groups. One group received $500 \mathrm{mg}$ pantothenol twice a week by injection, another received it orally and the third served as control and received propylene glycol by mouth or injection instead of pantothenol. Neither the patients nor the doctors conducting the trial knew the nature of the treatment given to any particular patient.

3. The results did not show any significant difference in the cures obtained between the control and treated groups of patients.

We are very grateful to Messrs F. Hoffmann-La Roche and Co. who supplied preparations of pantothenol and control substances in the way we required them. We are also indebted to Dr G. S. Ratnavale, M.D., M.R.C.P., Neurologist, General Hospital, Colombo, for helping us to decide on the clinical criteria for the selection of patients; to $\mathrm{Mr} \mathrm{H}$. A. Bibile for helping us to find patients who failed to report for treatment and persuading them to continue with it; and finally, to Dr M. D. K. Senaratne, who very kindly provided us with facilities at the rural hospital for conducting this trial.

\section{REFERENCES}

Bibile, S.W., Cullumbine, H., Watson, R. S. \& Wickremanayake, 'T. W. (1949). Ceylon F. med. Sci.6, 15. Burlet, E. (1944). Z. Vitaminforsch. 14, 3 I8.

Gopalan, C. (1946). Indian med. Gaz. 81, 22.

Nichols, L. \& Nimalasuriya, A. (I94I). Ceylon F. Sci. D, 5, 59.

Rubin, S. H. (1948). 7. Amer, pharm. Ass. 37, 502.

Rubin, S. H., Cooperman, J. M., Moore, M. E. \& Scheiner, J. (1948). F. Nutr. 35, 499.

Smith, D. A. \& Woodruff, M. F. A. (1951). Spec. Rep. Ser. med. Res. Coun., Lond., no. 274, p. I3r. 